\title{
Erratum to: Immunohistochemical diagnosis of Fabry nephropathy and localisation of globotriaosylceramide deposits in paraffin-embedded kidney tissue sections
}

\author{
Carmen Valbuena • Dina Leitão • Fátima Carneiro • \\ João Paulo Oliveira
}

Published online: 22 January 2012

(C) Springer-Verlag 2012

\section{Erratum to: Virchows Arch}

DOI: 10.1007/s00428-011-1182-y

The original version of the above mentioned manuscript, unfortunately, contained a mistake. Table 1 was published with the wrong version.

The authors very much regret their error.

The following is the updated version of Table 1.

\footnotetext{
The online version of the original article can be found at http://dx.doi. org/10.1007/s00428-011-1182-y.

C. Valbuena $(\bowtie) \cdot$ F. Carneiro

Department of Pathology, Hospital São João,

Alameda Prof. Hernâni Monteiro,

4200-319 Porto, Portugal

e-mail: valbuena@med.up.pt

C. Valbuena $\cdot$ F. Carneiro $\cdot$ J. P. Oliveira

Faculty of Medicine, University of Porto (FMUP),

Porto, Portugal

D. Leitão $\cdot$ F. Carneiro

Department of Pathology, Institute of Molecular Pathology and Immunology of the University of Porto (IPATIMUP),

Porto, Portugal

C. Valbuena $\cdot$ J. P. Oliveira

Department of Nephrology and Unit of Research \& Development

in Nephrology (FCT-725), Hospital São João,

Porto, Portugal

\section{J. P. Oliveira}

Department of Human Genetics, Faculty of Medicine,

University of Porto,

Porto, Portugal
} 
Table 1 Medical diseases affecting the kidney parenchyma, with histological vacuolization of cells [8-10]

\begin{tabular}{|c|c|c|c|c|c|c|c|c|}
\hline Disease & Podocytes & $\begin{array}{l}\text { Mesangial } \\
\text { cells }\end{array}$ & $\begin{array}{l}\text { Glomerular } \\
\text { capillary } \\
\text { endothelium }\end{array}$ & $\begin{array}{l}\text { Proximal } \\
\text { tubular } \\
\text { cells }\end{array}$ & $\begin{array}{l}\text { Distal } \\
\text { tubular } \\
\text { cells }\end{array}$ & $\begin{array}{l}\text { Interstitial } \\
\text { cells }\end{array}$ & $\begin{array}{l}\text { Vascular } \\
\text { smooth-muscle } \\
\text { cells }\end{array}$ & $\begin{array}{l}\text { Vascular } \\
\text { endothelium }\end{array}$ \\
\hline Aspartylglycosaminuria & + & & & & & & & \\
\hline Fabry disease & + & + & + & & + & + & + & + \\
\hline Fucosidosis & + & & & & & & & \\
\hline Gaucher disease & & & & & & + & & \\
\hline $\begin{array}{l}\text { Glycogen storage } \\
\text { disease type I }\end{array}$ & & & & + & + & & & \\
\hline GM1 gangliosidosis & + & + & & & & & & \\
\hline Hurler's disease & + & & & + & & & & \\
\hline I-cell disease & + & & & + & & & & \\
\hline LCAT deficiency & & + & + & & & + & + & + \\
\hline $\begin{array}{l}\text { Lipoprotein } \\
\text { glomerulopathy }\end{array}$ & & & & & & + & & \\
\hline Mannosidosis & + & & & & & & & \\
\hline $\begin{array}{l}\text { Metachromatic } \\
\text { leukodystrophy }\end{array}$ & & & & + & + & & & \\
\hline Nephrosialidosis & + & & & + & + & + & & + \\
\hline $\begin{array}{l}\text { Neuronal ceroid } \\
\text { lipofuscinosis }\end{array}$ & + & & + & + & + & & & \\
\hline Niemann-Pick disease & + & & + & + & + & + & & \\
\hline Sandhoff disease & + & & & + & & & & \\
\hline $\begin{array}{l}\text { Type III } \\
\text { hyperlipoproteinemia }\end{array}$ & & + & & & & & & \\
\hline Alport disease & & & & & & + & & \\
\hline $\begin{array}{l}\text { Nephrotic range } \\
\text { proteinuria }\end{array}$ & + & & & & & + & & \\
\hline Minimal change disease & & & & + & + & + & & \\
\hline
\end{tabular}

GM1: monosialotetrahexosylganglioside. LCAT: Lecithin:cholesterol acyltransferase. “+” vacuolization present 